\title{
NORTHERN HEMISPHERE ICE SHEETS AND PLANETARY WAVES: A STRONG FEEDBACK MECHANISM
}

\author{
M. LINDEMAN AND J. OERLEMANS
}

Institute of Meteorology and Oceanography, University of Utrecht, Princetonplein 5, 3508 TA Utrecht, The Netherlands

Received 18 June 1986

Revised 7 October 1986

\begin{abstract}
We carried out a statistical analysis of the relation between the net mass balance of high-latitude glaciers and $500 \mathrm{mb}$ height deviations of the seasonal mean atmosphere. Mass-balance series of 23 glaciers and ice caps were used, ranging in length from 8 to $30 \mathrm{yr}$. Considering the sample as a whole, it appeared that the only significant predictor for mass balance variations is the summer anomaly of the $500 \mathrm{mb}$ height. Except for a few individual glaciers, correlations with mean vorticity and meridional wind component turned out to be insignificant.

To investigate the potential feedback between ice-age ice sheets and planetary waves, we used a stationary two-layer atmospheric model to calculate the response to the CLIMAP (1976) ice-sheet topography for 18,000 YBP. Combining the result with the statistical analysis reveals that the feedback is important: the planetary-wave pattern forced by the ice sheets leads to deviations of the equilibrium-line altitude of about $500 \mathrm{~m}$.
\end{abstract}

KEY WORDS Glacier mass balance Vorticity Feedback Planetary waves

\section{INTRODUCTION}

One of the most striking features of the climatic history of the last few million years is the large variation in land ice volume stored on the northern hemisphere continents. Palaeoclimatologists have recognized this for a long time (e.g. Flint, 1971). However, it is only recently that the dynamic aspects of ice sheet growth and decay have received more attention. Various studies have shown that ice sheets form an active component of the climate system, and that a proper understanding and simulation of the quaternary glacial cycles cannot be achieved without dealing with the basic mechanics of ice sheets (Weertman, 1961; Oerlemans, 1980a; Pollard, 1982; Oerlemans and Van der Veen, 1984).

Ice sheets affect climate in various ways. The albedo feedback is probably studied most (Held and Suarez, 1974; Lian and Cess, 1977), and although estimates of the strength of this feedback differ, most workers agree on the fact that the sensitivity of climate to changes in the radiation budget is enhanced. The presence of ice sheets leads to a different geographical distribution of the radiation balance, of course, and this will certainly affect the atmospheric and oceanic circulation, and, subsequently, the hydrological cycle. This point has been investigated with zonal mean models (e.g. Oerlemans and Vernekar, 1981), and also with general circulation models (GCMs); see for instance Manabe and Broccoli (1985).

Although GCMs are probably the best tools to study how ice sheets influence the atmospheric circulation, they are at present not yet suitable for combined integration with ice-sheet models. The resolution is generally too coarse, and the calculation of the snow/ice mass budget at the surface cannot be done in sufficient detail. It seems likely, however, that this situation will change in the next ten years or so.

From a global point of view, large ice sheets (characteristic length scale: $2000 \mathrm{~km}$; characteristic surface elevation: $3 \mathrm{~km}$ ) must have a strong impact on the large-scale atmospheric flow. They form barriers of an extent at least comparable to the present major mountain ranges, and are thus likely to induce a strong planetary-

0196-1748/87/020109-09\$05.00

(C) 1987 by the Royal Meteorological Society 
wave pattern in the atmosphere. This establishes another feedback loop: snow accumulation and ablation depend on the large-scale atmospheric circulation, and an ice sheet may create more or less favourable conditions for further growth through the forcing of atmospheric waves. In this context, teleconnections form another interesting aspect. Suppose, for instance, that a large ice sheet is forming on the northern American continent. It would be interesting to know then whether the resulting atmospheric wave pattern would favour the growth of an ice sheet in northern Europe. Again, in principle, such questions can best be studied with highresolution GCMs, but 'intermediate approaches' may be useful too.

It is the purpose of this paper to study the potential importance of the feedback between ice sheets and planetary waves. Some discussions on this point can be found in the literature (e.g. Lamb and Woodroffe, 1970), but they are of a qualitative nature. Here we try to arrive at an order-of-magnitude estimate, based on observational data concerning the mass balance of a large sample of high-latitude glaciers and of the mean flow pattern ( $500 \mathrm{mb}$ height $)$ in the atmosphere. The purpose is to establish a general relation between glacier mass balance and quantities such as $500 \mathrm{mb}$ height, vorticity and meridional flow in the seasonal mean atmosphere. It will turn out that the $500 \mathrm{mb}$ summer anomaly is the most important factor.

The major mountain ranges in the Northern Hemisphere (Rocky Mountains, Himalaya) have a spatial scale similar to that of the ice sheets during a glacial period. The order of magnitude of planetary-wave amplitude induced by these ice sheets should thus be comparable to the amplitude we observe today. So a first estimate of the importance of the ice-sheet-planetary-wave feedback could be made directly from the statistical relation between glacier mass budget and $500 \mathrm{mb}$ height referred to above. We nevertheless carried out a computation concerning the forcing of planetary waves by the 18,000 YBP ice topography (CLIMAP, 1976) with a 2-layer atmospheric flow model. This model calculates the linear response, relative to a prescribed zonal mean state, and was originally developed by Opsteegh and Van den Dool (1980). Combining the resulting $500 \mathrm{mb}$ anomalies with the mass balance sensitivity then shows that the mechanism of ice-sheet-planetary-wave feedback is a powerful one!

In section 2 we present the data sources used and discuss the statistical analysis. The result from the 18,000 YBP experiment is presented in section 3, from which an order-of-magnitude estimate of the feedback is obtained. Some additional remarks are given in section 4.

\section{DATA AND STATISTICAL ANALYSIS}

Mass-balance data from 30 glaciers, all at latitudes higher than $50^{\circ} \mathrm{N}$, have been used in the present analysis. These glaciers are listed in Table I, in which references are given. In some cases, separate data are available for the accumulation and ablation season, in others not. For a number of glaciers the annual equilibrium-line altitudes have also been published.

Monthly and seasonal data on the height of the $500 \mathrm{mb}$ level are published by many weather services. We used a data set originally prepared by the Deutsche Wetterdienst (Offenbach).

Before calculating relations between anomalies in glacier mass balance and atmospheric parameters, we first considered the coupling of net balance, ablation (in the ablation season) and equilibrium line altitude (ELA). It turns out that the correlation between the net balance and the ELA is strong for all glaciers. Correlation coefficients are always larger than 0.85 , and most of them are larger than 0.92 . This result is not new, of course, but confirms earlier studies carried out on smaller data sets (e.g. $\emptyset$ strem, 1975). The relation between ablation and ELA is less pronounced, although significant for most glaciers. For both relations the regression coefficients differ widely, which is related to different glacier geometry and climate conditions. The variation of mass-balance anomalies with surface elevation depends strongly on type of glacier (maritime/continental; see Kuhn, 1984), so a universal regression coefficient cannot be expected. The full analysis is given by Lindeman (1985).

The following linear regression was applied to relate the net mass balance to relevant atmospheric parameters:

$$
B=C_{0}+C_{1} \phi_{\mathrm{w}}+C_{2} V_{\mathrm{w}}+C_{3} \zeta_{\mathrm{w}}+C_{4} \phi_{\mathrm{s}}+C_{5} V_{\mathrm{s}}+C_{6} \zeta_{\mathrm{s}}
$$

where $B$ is the net balance, $\phi_{\mathrm{w}}$ is the winter anomaly of $500 \mathrm{mb}$ height, $V_{\mathrm{w}}$ is the winter anomaly of meridional 
Table I. Glaciers and ice caps used in statistical analysis

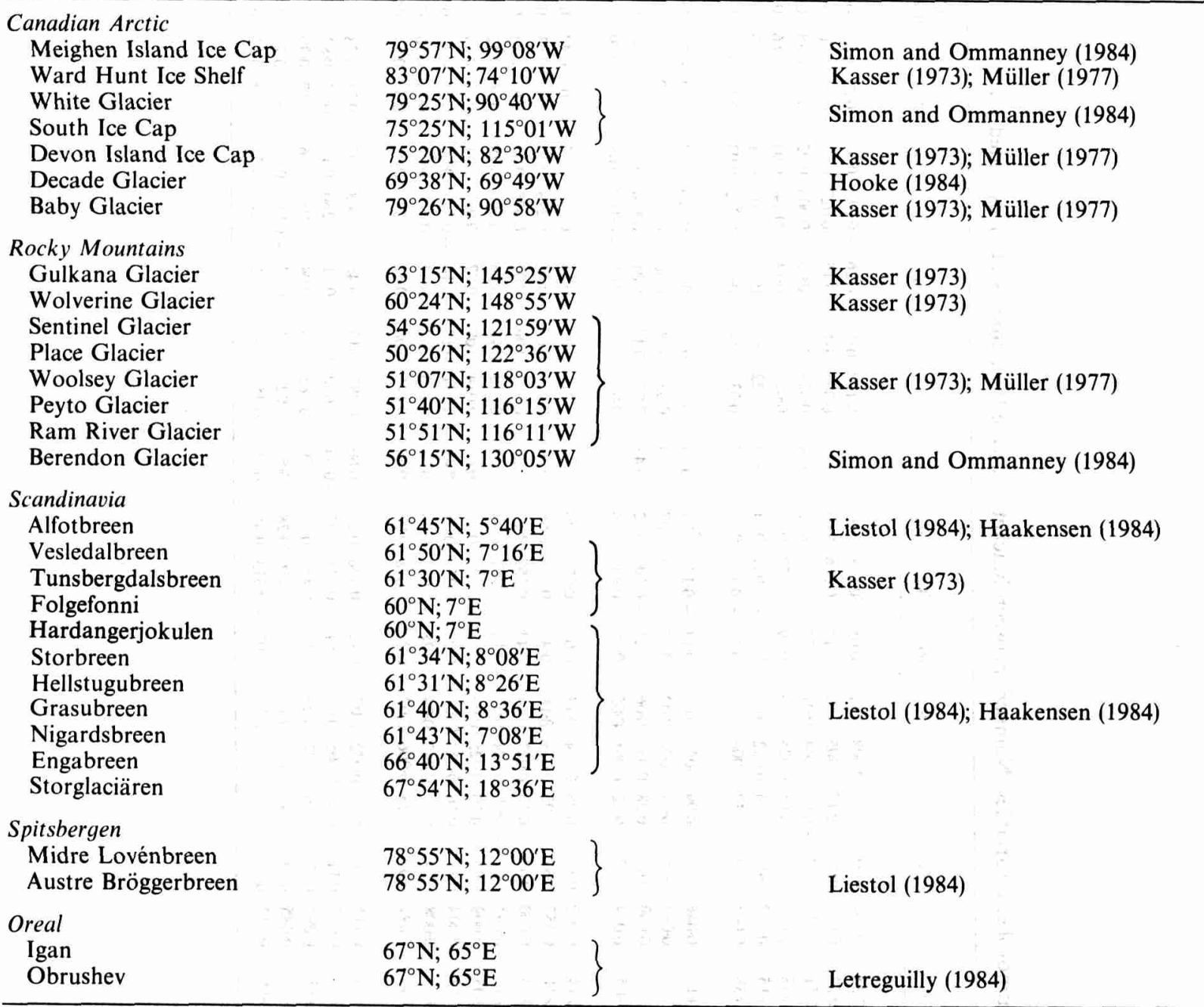

wind $(500 \mathrm{mb}), \zeta_{\mathrm{w}}$ is the winter anomaly of vorticity $(500 \mathrm{mb}), \phi_{\mathrm{s}}$ is the summer anomaly of $500 \mathrm{mb}$ height, $V_{\mathrm{s}}$ is the summer anomaly of meridional wind $(500 \mathrm{mb})$ and $\zeta_{\mathrm{s}}$ is the summer anomaly of vorticity $(500 \mathrm{mb})$. A southerly wind and cyclonic vorticity are considered as positive.

Although one can argue that autumn and spring anomalies may also be important, variables for these seasons were not considered because this would make the number of predictors too large for the short series considered.

The results of the regression analysis are summarized in Table II. Both the regression coefficient $c_{i}$ and the corresponding correlation coefficients $\rho_{i}$ are given. Values of the $c_{i}$ significant at the 5 per cent level are underlined. Apparently, the summer anomaly of $500 \mathrm{mb}$ height yields significant results $\left(C_{4}\right)$, and appears as the only important predictor for the interannual variability of the mass balance. For some other glaciers significant results show up for other predictors (the mass balance of Storglaciären, for instance, which has the longest mass balance series, is also related to the winter anomaly of the meridional wind and the summer anomaly of the vorticity), but the general picture is not very consistent. This finding is in agreement with other studies, in fact. Relating mass balance variations to local atmospheric parameters at the surface (temperature, 


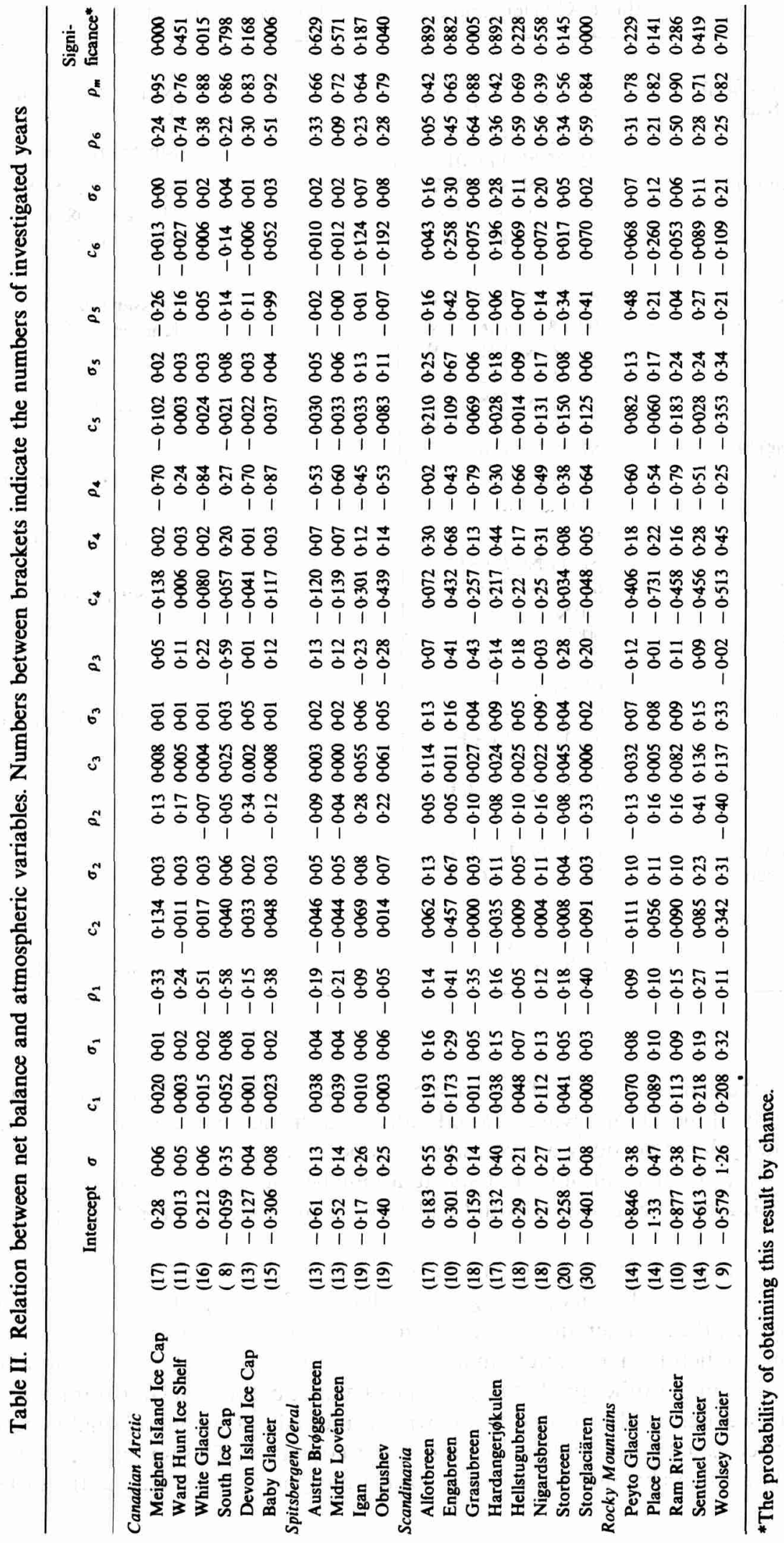




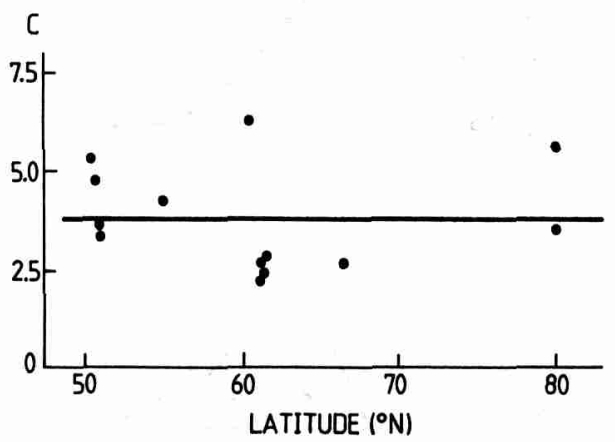

Figure 1. The relation between equilibrium-line altitude(ELA) and summer deviation of the $500 \mathrm{mb}$ height, in dependence on geographical latitude. Each point represents the constant of proportionality $(C)$ for a particular glacier or ice cup

precipitation) has shown that for most glaciers summer temperature is by far the most important factor (Letreguilly, 1984).

As an additional result we mention that there appears to be a systematic dependence of $C_{4}$ on latitude. The linear regression reads

$$
C_{4}=-0.13+0.0015 \varphi
$$

Here $C_{4}$ is in water equivalent per geopotential metre (gpm), $\varphi$ in ${ }^{\circ} \mathrm{N}$. It should be noted, however, that the atmospheric variability on long time scales increases with latitude (e.g. Oort, 1980). The actual mass-balance variations therefore depend less on latitude than suggested by the relation given above. Making use of the strong correlation between net balance and ELA, it is possible to relate the $500 \mathrm{mb}$ summer anomaly to the ELA. The result is fairly independent of latitude, as shown in Figure 1. The mean value of the constant of proportionality equals $3.7 \mathrm{~m} / \mathrm{gpm}$, with a standard deviation of $1.34 \mathrm{~m} / \mathrm{gpm}$.

\section{ATMOSPHERIC RESPONSE TO THE CLIMAP ICE-SHEET TOPOGRAPHY}

Whether the relation between $500 \mathrm{mb}$ summer anomaly and net mass balance is of real significance depends on the amplitude of the planetary-wave pattern induced by ice-sheet topography. To arrive at an order-ofmagnitude estimate, we calculated the linear response to the CLIMAP (1976) topography with the aid of a steady-state primitive equation model (described by Opsteegh and Vernekar, 1982). This model calculates the flow linearized around a basic reference state (zonal mean temperature and wind, depending on latitude and height). It has two layers (centred at 800 and $400 \mathrm{mb}$ ) and covers the entire northern hemisphere.

Since the model requires as input the zonal mean state, adjustments have to be made to the present-day zonal fields. As has been shown by various workers, the zonal mean atmosphere during a glacial period differs in a significant way from the present one. Here we use results from a zonal mean climate model that has been used to calculate equilibrium states for various imposed ice conditions (Oerlemans and Vernekar, 1981). For the present experiment the results for ice extent (land as well as sea ice) up to $60{ }^{\circ} \mathrm{N}$ were used. The relative deviations (i.e. with respect to a control run representing present-day conditions) of temperature and wind fields were employed to construct the 18,000 YBP zonal fields from those observed now (Oort, 1980). This procedure probably minimizes the effect of systematic errors. So we write

$$
X_{18}=\frac{X_{\text {mod,18 }}}{X_{\text {mod,pres }}} X_{\text {obs }}
$$

where the $X_{\text {mod,... }}$ are the present day and 18,000 YBP model values, $X_{\text {obs }}$ is the present day value and $X_{18}$ is the 18,000 YBP value to be used in the planetary-wave model. $X$ refers to either zonal mean temperature (at $600 \mathrm{mb}$ ) or zonal mean wind (at 800 and $400 \mathrm{mb}$ ). The resulting zonal mean fields (for summer) are shown in Figure 2.

The next step is to insert the CLIMAP topography in the planetary wave model. Since the shorter waves are 


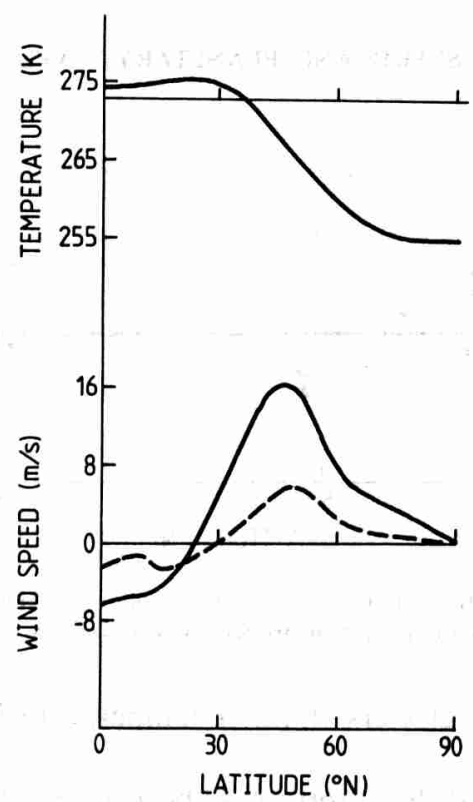

Figure 2. The zonal mean basic state of the atmosphere used to calculate the planetary-wave pattern for the CLIMAP topography. Air temperature is at the $600 \mathrm{mb}$ level, zonal mean wind (westerly wind is positive) at the $400 \mathrm{mb}$ (solid) and $800 \mathrm{mb}$ (dashed) levels

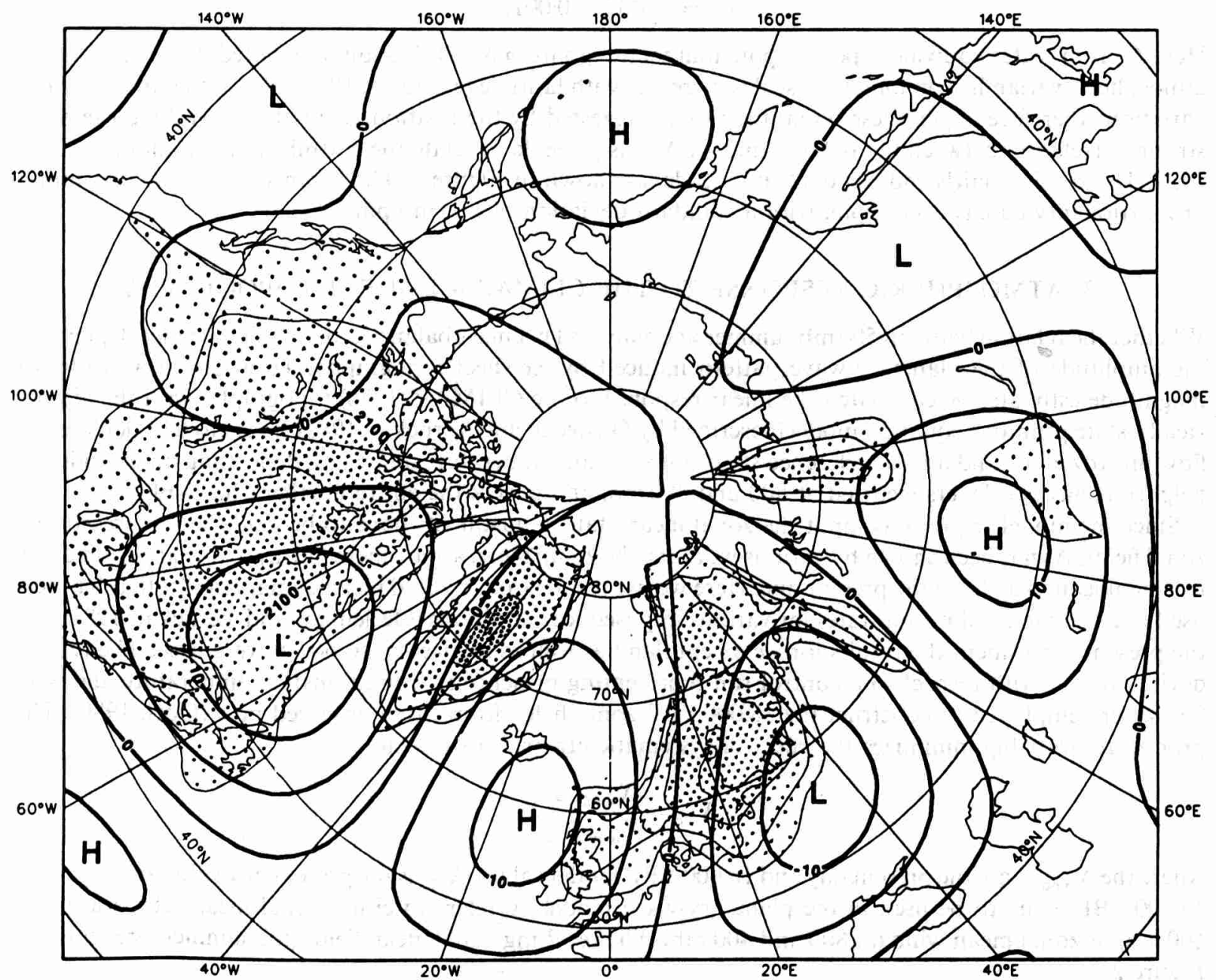

Figure 3. Perturbation of $500 \mathrm{mb}$ height (geopotential dam) due to topographic forcing by the 18,000 YBP ice sheets. Stippled areas represent the ice sheets (surface elevation in $1000 \mathrm{~m}$ intervals). The heavy lines give the planetary wave pattern 


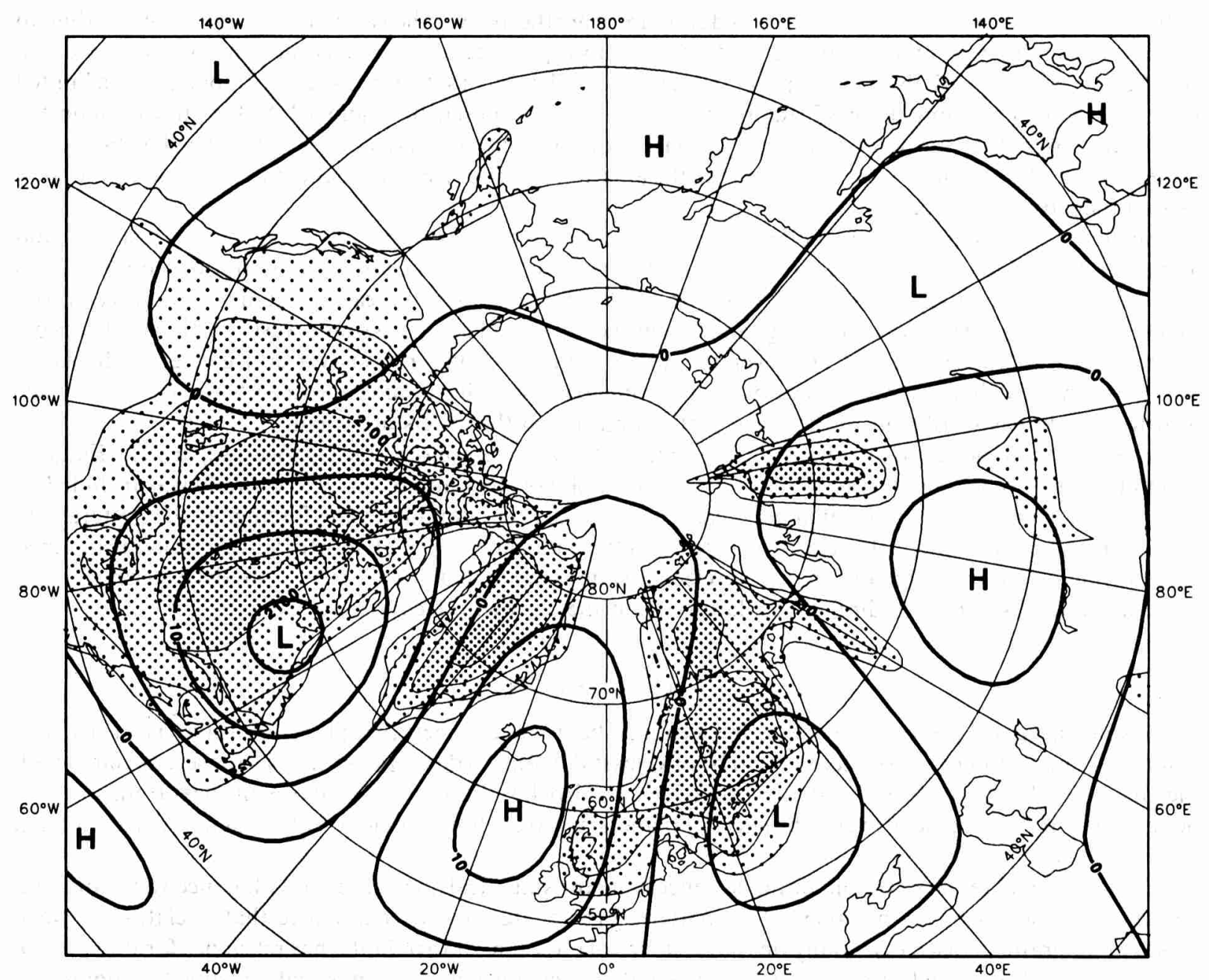

Figure 4. As in Figure 3, but now for forcing by the Laurentide ice sheet only

strongly damped, there is no reason to use a high resolution. The topography was therefore read out on a 5 to 5 degree grid. Obviously, the main forcing comes from the Laurentide and Fennoscandian ice sheets.

Some results of the computations are shown in Figure 3. Since the statistical analysis of the foregoing section showed that the planetary-wave pattern in summer is most important, the zonal mean state for summer was used as the basic state. Apparently, the atmospheric response to the CLIMAP topography is dominated by wave number three. The largest deviations in geopotential height are found in the vicinity of the main forcing regions: a minimum of -14 dam near the Laurentide ice sheet and a maximum of +12 dam just west of the Fennoscandian ice sheet. It should be noted that the result obtained here is in fairly good agreement with a similar experiment carried out with a GCM (Manabe and Broccoli, 1985; their Figure 10). In the GCM experiment thermal forcing is also included, but for middle and high latitudes the orographic forcing seems to be the most important factor.

If we interpret the isohypses as deviations of the ELA, the planetary-wave pattern implies that ice-sheet growth is favoured at the eastern sides. Maximum deviations of the ELA are of the order of $400-500 \mathrm{~m}$. It is noteworthy that the ELA decrease associated with the trough is of a magnitude similar to the decrease required to initiate ice sheets in the Northern Hemisphere (Charlesworth, 1957; Andrews and Mahaffy, 1976; Oerlemans, 1980b). So the planetary wave feedback must be an important factor once the ice sheets have grown to a $1000 \mathrm{~km}$ scale, say. 
It is also interesting to see that the flow is dominantly northerly over the two major ice sheets. According to the statistical analysis of net balance and $500 \mathrm{mb}$ flow patterns discussed earlier this would be of no significance, but it is probably too simple to put it that way! The fact that year-to-year variability over a limited time span does not show a significant relation between meridional flow and ELA does not exclude the importance of northerly flow found here for glacial conditions. In summary, it appears that the planetary-wave pattern induced by the ice sheets acts to reduce the ablation (positive feedback), and may be the accumulation as well (negative feedback).

The linear atmospheric flow model used here was tuned to present-day conditions (Opsteegh and Vernekar, 1982). Dissipation in the model is most important in this respect, and some additional computations were carried out to study the sensitivity of our results. For instance, increasing the dissipation leads to a planetary-wave pattern in which the ridge and trough axes are tilted more in a south-west-north-east direction, whereas the amplitude is reduced. However, the typical high/low configuration over the ice sheets as displayed in Figure 3 hardly changes. Also, variations in the zonal basic state have some influence. Stronger zonal winds lead to a slight eastward shift of the wave pattern, but again the effects are small.

Since the atmospheric model is linear, it is simple to study the response to the ice sheets separately. Figure 4 shows the result of an experiment in which the topography of the Laurentide ice sheet only was included. A comparison with Figure 3 immediately reveals that this ice sheet dominates the forcing, as the patterns are similar. The reason for this is the selective damping of the atmospheric model: shorter wavelengths are damped more strongly. However, conclusions about teleconnections are difficult to draw. Here model experiments in a more dynamic fashion (including a calculation of ice sheet growth/decay) are needed.

\section{DISCUSSION}

The results discussed above suggest that the feedback between ice sheets and planetary waves is strong. The associated changes in mass balance seem to be of at least the same order of magnitude as those associated with the albedo feedback, ice-sheet surface lowering due to bedrock sinking, changes in oceanic heat transport, etc. So in future studies of glacial cycles the effect of planetary waves should preferably be taken into account in a dynamic way.

A few additional remarks should be made concerning the statistical analysis of mass-balance variations and deviations in the seasonal atmospheric flow pattern. First of all, it has been assumed that a relation between these two quantities, based essentially on the existence of interannual variability, has relevance for the study of climatic variability as well. It is difficult to say whether such a generalization is really justified, although we expect that orders of magnitude are right. Accumulation poses particular problems. In many climates where glaciers are found, most of the precipitation falls in relatively short time periods (a few storms can make the bulk of a season's precipitation). However, this is hardly reflected in, for instance, a relation between precipitation and seasonal mean vorticity of the large-scale atmospheric flow. One might hope that future experiments with GCMs will help to clarify these points. However, the growth of an ice sheet is the result of a very small imbalance between accumulation and ablation, and at present GCMs do not seem to simulate hydrological processes at the surface with sufficient accuracy.

In the future we plan to do dynamic model experiments following an 'intermediate approach'. This involves coupling of an ice-sheet model, covering the entire northern hemisphere, with an atmospheric flow model as used here. The ice-sheet model is then integrated in time, and a diagnosis of the planetary-wave pattern, with associated changes in the mass balance, is done every 500 years, say. Some preliminary experiments with such a combined model clearly showed that the treatment of accumulation is critical to the results. It became clear that without explicitly taking into account the orographic effects on the distribution of precipitation meaningful results cannot be obtained. In fact, a moisture equation has to be included, possibly in the same way as was done for the Scandinavian ice sheet by Sanberg and Oerlemans (1983). They showed that the feedback of ice-sheet topography and accumulation is a very important factor in the evolution of an ice sheet.

Finally, we hope that the statistical analysis of mass-balance variations presented here will be of value for other, more local, studies of glacier variations and climatic change. 


\section{ACKNOWLEDGEMENTS}

We are grateful to Theo Opsteeg (Royal Netherlands Meteorological Institute) for putting at our disposal the planetary-wave model. We also thank Robert Mureau for further help concerning the use of this model. Useful comments on an earlier version of this paper came from Wouter Greuell and Cor Schuurmans.

This work has been sponsored by the Climate Programme of the Commission of the European Communities, under contract CLI-101-NL (N).

\section{REFERENCES}

Andrews, J. T. and Mahaffy, M. A. W. 1976. 'Growth rate of the Laurentide ice sheet and sea level lowering (with emphasis on the 115000 YBP sea level low)', Quaternary Res., 6, 167.

Charlesworth, J. K. 1957. The Quaternary Era, Edward Arnold, London.

CLIMAP Project Members. 1976. 'The surface of the ice-age earth', Science, 191, 1131.

Flint, R. F. 1971. Glacial and Quaternary Geology, Wiley, New York.

Haakensen, N. 1984. Glasiologiske undersokelser $i$ Norge 1981, Norges Vassdrags- og Elektrisitetsvesen, Oslo.

Held, I. M. and Suarez, M. J. 1974. 'Simple albedo feedback models of the ice caps, Tellus, 26, 613.

Hooke, R. L. 1984. Personal communication.

Kasser, P. 1973. Fluctuations of Glaciers 1964-1970, IAHS/UNESCO, Paris.

Kuhn, M. 1984. 'Mass budget imbalances as criterion for a climatic classification of glaciers', Geografiska Ann., 66A, 229.

Lamb, H. H. and Woodroffe, A. 1970. 'Atmospheric circulation during the last ice age', Quaternary Res., 1, 29.

Letreguilly, A. 1984. Bilans de Masse des Glaciers Alpin: Methode de Mesure et Repartition Spatio-temporelle, Laboratoire de Glaciologie, Grenoble.

Lian, M. S. and Cess, R. D. 1977. 'Energy balance climate models: a reappraisal of ice-albedo feedback. J. Atmos. Sci., 34, 1058.

Liestol, O. 1984. Personal communication.

Lindeman, M. W. 1985. Parameterization of the Net Balance of Northern Hemisphere Glaciers with 500 mb Height Anomalies, Institute of Meteorology and Oceanography, University of Utrecht, Rep. R-85-7.

Manabe, S. and Broccoli, A. J. 1985. 'The influence of continental ice on the climate of an ice age', J. Geophys. Res., 90C, 2167.

Müller, F. 1977. Fluctuations of Glaciers 1970-1975, IAHS/UNESCO, Paris.

Oerlemans, J. 1980a. 'Model experiments on the 100000 yr glacial cycle', Nature, 297, 550.

Oerlemans, J. 1980b. 'Modelling of Pleistocene European ice sheets: experiments with simple mass-balance parameterizations', Quaternary Res., 15, 77.

Oerlemans, J. and Van der Veen, C. J. 1984. Ice Sheets and Climate, Reidel, Dordrecht.

Oerlemans, J. and Vernekar, A. D. 1981. 'A model study of the relation between Northern Hemisphere glaciation and precipitation rates', Contr. Atmos. Phys., 54, 352.

Oort, A. H. 1980. Global Atmospheric Circulation Statistics, 1958-1973, NOAA Prof. Paper 14.

Opsteegh, J. D. and Van den Dool, H. M. 1980. 'Seasonal differences in the stationary response of a linearized primitive equation model: prospects for long-range forecasting?' J. Atmos. Sci., 37, 2169.

Opsteegh, J. D. and Vernekar, A. D. 1982. 'A simulation of the January standing wave pattern including the effects of transient eddies', $J$. Atmos. Sci., 39, 734.

$\emptyset$ strem, G. 1975. 'ERTS data in glaciology - an effort to monitor glacier net balance from satellite imagery', J. Glaciol. 15, 403.

Pollard, D. 1982. 'A simple ice-sheet model yields realistic $100 \mathrm{kyr}$ glacial cycles', Nature, 296, 334.

Sanberg, J. A. M. and Oerlemans, J. 1983. 'Modelling of Pleistocene European ice sheets: the effect of upslope precipitation', Geol. Mijnbouw, 62, 267.

Simon, C. and Ommanney, L. 1984. Canadian Glacier Variations and Mass Balance Changes, National Hydrology Research Institute, Canada.

Weertman, J. 1961. 'Stability of ice-age ice sheets', J. Geophys. Res., 66, 3783. 